\title{
Preventive Service Management: Towards Pro-Active Improvement Of Service Quality
}

Ofer Barkai, Shamoon College of Engineering, Israel

Elad Harison, Shenkar College of Engineering and Design, Israel

\begin{abstract}
The operation of service providing systems and organizations is challenging, as services typically incorporate a broad set of resources and a complex and sophisticated work practices that fulfill the needs of different consumers. At the same time, the lack of resources allocated for service operations or their mismanagement can yield negative results that are likely to affect customers' experiences. The paper devises a new framework for implementing preventive service systems that manage complaint prevention operations. Such complaint management may proactively avert service malfunctions and consequent customer complaints. The framework is based on extensive use of IT systems that continuously monitor the infrastructure for service provision in a cycle of activities that includes detection and prevention of service failures, notification of service malfunctions to customers as a part of their service provision, and follow-up operations. The implementation of the framework presented is exemplified by the case of a large telecommunications operator.
\end{abstract}

Keywords: Preventive Service Management; Service Failures; Customer Complaints; Information and Communication Systems; Customer Satisfaction

\section{INTRODUCTION}

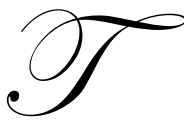

he eminent growth of service industries worldwide and the role of services in the activities of most of the firms virtually in every industrial and technological sector highlight their major economic and commercial importance. Companies, customers and economists have recognized the value that services provide both to customers and to firms and the additional profits that service provision contributes in many sectors, including traditional industries, manufacturing, retail and ICT.

The operation of service providing systems and organizations is challenging, as services typically incorporate a broad set of resources, complex organization and work procedures that fulfill the various needs of different consumers. At the same time, service providers aspire to ensure their customers' satisfaction, the proper functioning of their firms and their profitability. On the other extent, lack of resources allocated for service operations or their mismanagement can yield negative results that are likely to affect the experiences of customers, the perceived quality of services, the reputation of firms and levels of trust and loyalty among customers. Consequently, service providers may experience loss of market share and revenues (Duffy, Miller, and Bexley 2006).

The literature on planning, operation and management of services has emphasized the importance of customer complaint management and its application as means for sustaining customer satisfaction. Customers complain when they suffer damages or discomfort from the provided services or, more generally, when the expected value of the service is lower than the actual service quality and performance. However, many customers choose to leave their service provider without expressing their discomfort. Doing so, they do not enable the provider to correct its dissatisfying activities, earn their trust or compensate them (Chebat, Davidow, and Codjovi 2005; Sharma et al. 
2010). Further, complaint management can be utilized to identify systemic failures in the provision of services (see for example Fornell and Wernerfelt 1987; Hart, Heskett, and Sasser 1990; Miller, Craighead, and Karwan 2000).

While customer complaint management particularly focuses on the correction of the dysfunctional actions and elements of the firm that result in maltreating customers, preventive service activities can reduce the volume of dissatisfying events. Preventive service is based on the application of human-based procedures and automated systems that aim at proactively prevent outages and malfunctions in the delivery of services. Fornell and Wernerfelt (1987) highlight the importance of preventing dissatisfying provision of services by applying defensive marketing strategies that are "concerned with reducing customer exit and brand switching", minimizing customer turnover and maximizing customer retention by protecting products and markets. The authors highlight a proactive set of actions targeted towards retaining customers by effectively addressing their complaints and learning from them about occurrences of failures in services and in operations, which can be treated and eliminated by the organization. Bolton (1998) argues that the length of the relationship between a customer and a provider depends on the degree of customer satisfaction and is determined by the expected value this relationship for the customer and by her service experience. The duration of customer-provider relationship is influenced especially by the frequency of service failure events.

Since customer satisfaction decreases with the amount and with the magnitude of service failures that they experience, the expected value of the service and the economic gains of customers decrease too. The link between customer satisfaction and retention and the profitability of the firm has been shown in numerous studies concerning service management (see, for example, Anderson Anderson, Fornell, and Lehmann 1994; Rust, Zahorik, and Keiningham 1995; Loveman 1998; Gupta and Zeithaml 2006). When the likelihood of customers sustaining their relations with the service providing firm and their propensity to use its services decrease over time, the firm's profits would decrease as well in the long run (Johnston, 2001).

Maxham and Netemeyer (2002) highlight the importance of recovery efforts following a complaint in the context of multiple service failures. They suggest that firms can improve the loyalty of customers that experience service failures if these events are successfully resolved. However, when service failures frequently occur or when customers are often maltreated, their perception of the firm would be severely harmed. Consequently, customers are likely to leave the service provider and share their experience and dissatisfaction with others. Yet, repeated service failures can often be prevented, had customers' complaints been utilized by organizations as means for monitoring and signaling malfunctions in their operations (Davidow 2003).

Prevention of faults and failures has generally been explored in broad venues of the academic literature. Notably, studies on logistics and maintenance elaborated various aspects in fault prevention policies, the use of IT in planned maintenance and in identifying mal-operating systems and the economic value of preventing faults (Luo and Bhattacharya 2006). Interestingly, however, very little theoretical or empirical research has been conducted on preventing faults in service processes, with the exception of healthcare studies (see, for example, Tucker and Edmonson 2003). By increasing the attention to fault prevention in services among organizations and managers in every field, firms can effectively improve the level of delivered services while sustaining the satisfaction of their customers. This aim can be accomplished by applying a framework upon which organizational and technological systems that monitor the various operations of services can be developed to prevent service failures.

The availability vs. profitability paradox suggests that two opposite motions affect the provision of services when the demand for them is high. On the one hand, Rust and Chung (2006) argue that during peak periods the capacity of the firm to provide services is fully utilized. On the other hand, the profitability of the firm increases during peak periods, as customers are more willing to pay higher prices to be served (Radas and Shugan 1998). These insights suggest that, from the firm's operations standpoint, peak periods become critical, as the firm experiences increasing demand. The demand often leads to over-utilization of the firm's resources and to service malfunctions, while it attempts to sustain the level of service provision to protect its reputation and to enhance its income. Therefore, it is important to monitor the breadth of processes and systems that are related to the firm's services or that may affect them to prevent service failures, especially during high demand periods. 
The aim of the paper is to devise a new framework and methodology for the implementation of preventive service systems. The methods presented and the information systems developed to support their operation can be applied in a wide range of organizations, firms and processes.

The paper is constructed as follows: Section 2 presents the constructs of the preventive service framework and elaborates them in depth, in view of the existing research on services and service-based operations. This section also presents in details the methodology for the prevention of service failures that was devised on the basis of the aforementioned conceptual framework. Section 3 presents a case study of the implementation of a preventive service system developed and applied on the basis of the presented methodology. Section 4 elaborates the findings of the case study and concludes how they comply with the literature and can be applied in different firms.

\section{PREVENTIVE SERVICE MANAGEMENT: A CONCEPTUAL FRAMEWORK}

\subsection{Background}

The application of preventive service systems in a broad range of organizations requires a coherent and constructed framework that can address a wide spectrum of services, processes and industrial sectors.

Our methodology aims at elaborating the aspects of the preventive service in a coherent manner by establishing a model that includes the following stages: detection, prevention, notification and follow-up (see Fig. $1)$.

Detection encompasses the continuous monitoring efforts and activities that the organization implements to terminate the possible occurrence of complaint-yielding and dissatisfactory events. The stage is continuously operated on the service infrastructure that serves a selected group of customers (such as the most substantial profit yielding customers) or on the mechanisms that serve the complete populace of customers.

Automation of detection processes via real-time control and technical information systems is especially important due to the possibilities of widespread coverage of the service providing infrastructure and accessing a large group of customers (such as in the case of monitoring problems in power and cable grids). Further, the firm can economize on labor costs by eliminating the need for employing monitoring teams.

Prevention represents the activities that the system implements to eliminate risk factors that may affect the proper provision of services, aiming at sustaining their quality. In this stage, the system performs a determined set of activities that proactively prevent the occurrences of service failures. For examples, if network failures are discovered (as in the case of power grids or communications networks), the system transfers the provision of utilities to an alternative infrastructure, carries out emergency and contingency operations to prevent further damages, alerts maintenance teams and requests their immediate intervention.

Notification provides information about the service failure event to the customers who are likely to be affected by it or customers the firm finds it important to alert. Notification pertains to situations in which any damages occur or even when the event goes unnoticed by customers. At this stage, the firm notifies the customers who are likely to be affected by the service failure about the problem and the major steps that are taken to solve it. The notification takes place regardless of whether the failure is ongoing or if it were resolved (thereby notifying customers about this occurrence ex-post). Notifications about the service failure are delivered to customers in parallel to preventive operations or can be activated after the prevention is completed.

Follow-up concludes the preventive service cycle. It aims at supporting customers, providing detailed information about the event if any inquiries are delivered, addressing their complaints and offering them assistance due to the service recovery strategies that the firm applies (for example, by apology or compensation; see Maxham 2001). Further, the outputs of the follow-up stage can provide indicators for analyzing malfunctions in service processes that can prevent similar events in the future. 


\section{Preventive Service Management}

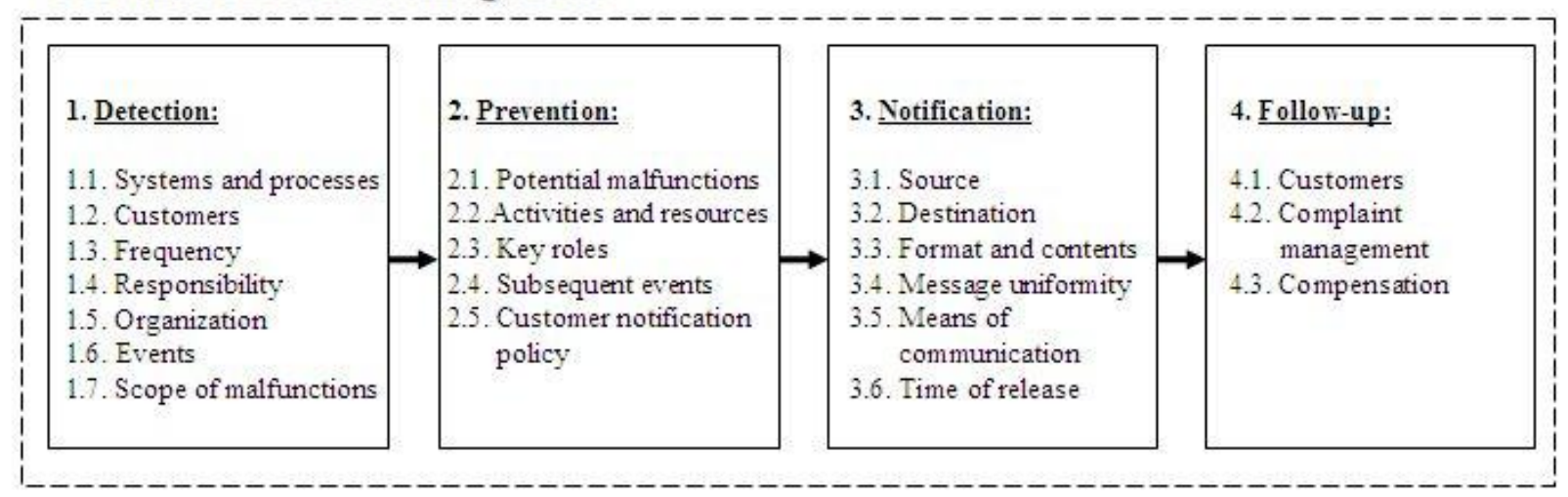

Figure 1: Stages of the Preventive Service Management process

The architecture of preventive service systems is usually based on a passive system that notifies customers about service outages when they call the service provider to seek solution or to complain. However, the system can also include an active mechanism that proactively notifies a selected population of customers about service malfunctions when they are discovered, or even when upcoming disruption may occur with high probability.

\subsection{Detection}

Detection represents a set of continuous operations that are carried out by the service provider to discover service failures within the shortest time from their occurrence. This stage aims at minimizing the disturbances and damages caused to customers by service malfunctions by detecting potential factors that may cause shortages in provision of services or service malfunctions as soon as they occur.

The detection of service malfunctions is not only associated with service quality and with the consequent degree of customer satisfaction, but it also affects the income of service providers, causing both direct and indirect losses. Most of the service operations generate a stream of revenues, which can result either from a limited group of consumers, each paying high fees, or from a large population of customers, each contributing different scale of surplus to the firm. During the period of service malfunctions or a timely termination of services, customers cannot use the services and the income of the provider decreases in proportion to the service malfunction period, thus resulting in direct losses. Additionally, when the provision of services (such as electricity or communications) is essential for the operations of customers, they may suffer financial and operational damages that are usually compensated for by the service provider (due to contractual obligations, judicial decision or goodwill). Consequently, service providers may also suffer indirect losses.

As detection processes are often lengthy, costly and labor extensive, firms should implement automated systems that monitor and test their service provision infrastructure and facilities on a continuous basis. Information systems can fulfill these aims and should address the following dimensions in their design and operability:

Systems, operations and processes that should be monitored - First, the organization has to determine which business operations should be monitored by the automated system. Then, the set of business processes, the infrastructure and the technical systems that carry them out are identified. These elements are the subject of the detection activities and should be included in the scope of the operations of the automated detection mechanisms.

The population of customers for which detection is carried out - Generally, the organization can monitor the services provided to the complete population of customers. Yet, this decision can prove costly and, in some cases, unfeasible. Alternatively, service providers can focus on particular groups of customers that contribute the largest 
profits or on those that the services of the firm are critical for their operations (such as hospitals, in the case of water and energy supply).

The frequency of detection activities - The logic of detection activities is based on sampling the system status every period of time. This time duration can be short in the case of continuous detection or long when non-continuous detection mechanisms are applied (e.g. once every five hours or four times a month). As detection operations are more frequently activated, the likelihood of identifying service malfunctions increases, but the detection operating costs would increase too. Firms should evaluate the elasticity of service quality to detection costs to determine the optimal investment in prevention mechanisms, as well as the frequency of activating them.

Responsibility for different detection operations - In general, firms should organize their detection activities in the form of uniform responsibility, in which all detection activities are performed by a single unit within the organization, e.g. the technical department, or by distributing responsibilities for different types of systems, services, operations or clients between various organizational units. As service operations are often interlinked (due to the complex structures of service provision mechanisms), when responsibilities are allocated to different organizational units, a coordinating body should be established.

How detection operations are organized and carried out - Service providers should allocate ICT, human and technical resources that are necessary to monitor and detect their service providing infrastructure and channels to the selected customers. These resources should be organized to achieve the defined service quality level of each operation with the maximal degree of efficiency.

Events defined as service malfunctions - The organization has to determine the types of occurrences that are considered as service malfunctions. These events can vary due to the expected service quality and due to the types of services that the organization provides. For example, when a phone line does not function more than ten minutes, the event can be defined as a service malfunction. Alternatively, when data transfer on a network cable is delayed over ten milliseconds due to "network bottlenecks" and excessive use, the event can also be considered as service a malfunction.

The scope of the service malfunction - When a service failure is identified, the unit responsible for its detection has to determine whether the service failure is "local" (i.e. it affects only a limited group of customers) or systematic (an event that affects a large population) and what is the expected duration of the service outage.

\subsection{Prevention}

Prevention represents the set of activities that aim at eliminating service malfunctions, when they are discovered, to ensure continuity and the quality of services. Prevention processes primarily aim at improving the quality of services by reducing the volume of unexpected occurrences that hamper their provision. Nonetheless, in the case of planned service outages, when maintenance operations are carried out, prevention includes the organization of activities and resources that can shorten the duration of service malfunctions and minimize financial losses.

Prevention activities are derived from the capabilities of the infrastructure and the systems that maintain them. In some organizations, part of the service failures due to technical reasons (such as operating system failures) can be remotely resolved, while other types of events or equipment require on-site visits by technicians and engineers.

Our framework consists of the following aspects of prevention processes:

Identifying potential service malfunctions - Service providers can largely benefit from identifying, "classifying" and addressing the issues associated with potential service failures or with inefficiencies in the maintenance of their infrastructure. Organizations should articulate in advance plans to resolve potential service failures. 
Activities and resources for resolving technical malfunctions - Organizations should perform preventive activities by allocating and prioritizing necessary means to prevent service failures from occurring. The allocation of resources can also be decided on an economic basis. Given particular financial constraints, service providers can decide to invest in preventing only the failures that cause damages that surpass the costs of the resources, without taking into account downgraded service quality and reputation.

Key roles within the organization informed about preventing service malfunctions - As service malfunctions occur and are prevented, automatically or by technicians, stakeholders within the organization (such as the CEO, technical experts and customer service managers) should be informed about the events and the solutions provided to customers. This information can serve as a useful input in decision making processes within the firm, including investments in improving the service delivery infrastructure or customer relationship management (CRM) processes.

Subsequent events that should be prevented - Service malfunctions may trigger additional service failures that may expand the scope of damages that both customers and service providers experience. Firms can broaden the scope of preventive service management by addressing processes and systems that can fail as a result of service malfunctions and by defining precaution steps that follow the occurrence of such an event or its prevention.

Customer notification policy about prevented malfunctions - When a service failure is detected and prevented, the organization should decide whether to notify its customers about it, even when no damages or service distractions were experienced. On the one hand, notifying customers about service failures may enhance the transparency of the service provider's operations and can improve the trust and the loyalty of customers. On the other hand, frequent notification may (rightly or wrongfully) signal low service quality and can deter customers from renewing their contracts. Thereby, the firm should strike a balance between these opposite motions by selecting the group of customers that receive its messages and by choosing which events would initiate their release (see also Section 2.4 below).

\subsection{Notification}

Notification represents the set of activities, communication means and messages sent to customers that are activated by the firm when a service failure event is expected, prevented or resolved.

Firms usually operate a passive notification mechanism, which alerts customers about service failures in their area or in their system only after contacting the provider's helpdesk. This mechanism is supported by service representatives or via an automated response system. The system tracks the identity and the location of customers and notifies them via a recorded message about relevant service malfunctions and the steps taken to solve them.

The proposed framework suggests that by applying the passive notification in an automated way, the firm can address a large volume of customer calls in cases of widespread service failures. Additionally, the framework also suggests that firms should implement additional active notification systems that pro-actively contact customers and deliver notifications about expected service failures (mostly due to planned maintenance activities) or those that are discovered and can affect the operations of customers.

Nonetheless, firms that decide to implement passive and active notification systems should be aware of the following aspects:

The source of notifications - Who are the organizational units or contact persons that are in charge of notifying customers? Do different organizational departments or a single department (as the customer care department) contact customers in different occasions? Who should approve the delivery of notifications to customers? To whom the handling of notification delivery should be reported after it is completed?

The destination of notifications - Who are the contact persons in the customer organizations? Who are the alternative receivers of the messages? Under which terms that should be contacted (e.g. only during the workday or also after work hours)? Which sub-groups of the clientele should be notified? How can the contact details of the selected group of customers to be notified be retrieved? 
The format and the contents of the message - Which information is included in the messages? In which format should messages be sent out? Messages can include a short description of the service malfunction, the expected duration of it and details of the contact person that can provide further information and assistance.

Uniformity of messages - the organization can choose between delivering a uniform message to customers and sending different messages to different groups of customers, due to their needs or inherent attributes, such as the degree of importance of the service for each customer or the expected damages that result from the malfunction.

Means of communication - The organization should establish reliable and continuous communication channels with its customers that can function even when services are terminated. The means of communication can vary from one customer to another and include SMS, emails, phone calls and access allowances for placing service alerts in the client's online portal. The selected means of communication should be independent from the provided service, in order to prevent failure in notifying clients when malfunctions occur. For example, mobile operators should send messages to customers via email, rather than calling their mobiles or sending them SMS.

The time of releasing notifications to clients - Service providers should decide on the time of notifying customers (or different groups of customers) about service malfunctions. For example, once at a given time after the detection of the malfunction (in the case of an unexpected event), clients can be notified every couple hours after a service failure is identified, when a particular maintenance stage is completed, or several days before an expected service termination due to maintenance activities.

\subsection{Follow-up}

Follow-up is the last stage of the preventive service management process. It aims at identifying the set of activities that ensure customer satisfaction and an ongoing improvement after a service failure is prevented.

The follow-up stage consists of the following aspects that should be designed by the organization:

Selected group of customers that are contacted - The group of customers contacted after a service failure is prevented are usually the most important and profitable for the service provider. For example, the organization can ensure that these customers are notified in time about service malfunctions and do not suffer any damages. The firm can also discover whether any compensation should be paid for any related losses.

Complaint management - Service providers should address customer claims as a part of the complaint management and customer care processes. These claims, when properly managed, documented and analyzed, can provide useful insights on the efficiency of the preventive service management operations and aspects of them that should be broadened or improved.

Activating compensation schemes - Often, after addressing customer complaints, service providers have to compensate for damages that customers suffered during service outages. The compensation can be either financial or non-financial (see review of different compensation methods in Maxham and Netemeyer 2002).

\section{APPLYING THE PREVENTIVE SERVICE FRAMEWORK: THE CASE OF A LARGE TELECOMMUNICATIONS COMPANY}

\subsection{Background}

This section presents the use of the preventive service methodology and its applications in Telco, one of the largest telecommunication companies in Israel. The company provides various types of services (such as telephone lines, broadband networks, VoIP and data transmission) to over 2.4 million business and private customers.

The services provided by Telco are subject to faults and outages that usually affect their end-users. The service support center of the firm receives approximately on average 270000 calls from business sector customers per month. Service representatives can monitor the customer's telephone line by sending an electronic signal over 
the line that indicates whether the line is faulty or not. If the return signal is defective, the problem is analyzed by the monitoring information system and the fault report is passed on to the appropriate technical department. The firm operates different departments that handle various segments of the services and the infrastructure, such as telephone exchange maintenance, telephone line maintenance, and backbone cable maintenance.

The different departments handle about 70 thousand faults per month. On average, there are 28.97 monthly faults for every thousand lines. The rate of repeating faults on the same equipment is approximately $6.5 \%$.

This service division of the firm consists of a service support center, technical support teams for repairing faulty equipment and a computer system that supports the fault identification and handling process. The service operating zone is divided into several geographical units, where each geographical area has its own technical support team.

The top percentile of the firm's customer base consists of "VIP customers" that generate $45 \%$ of its income from the business sector. Since the uptime of lines of these customers directly affects Telco's earnings, the company prioritizes handling service faults in their infrastructure.

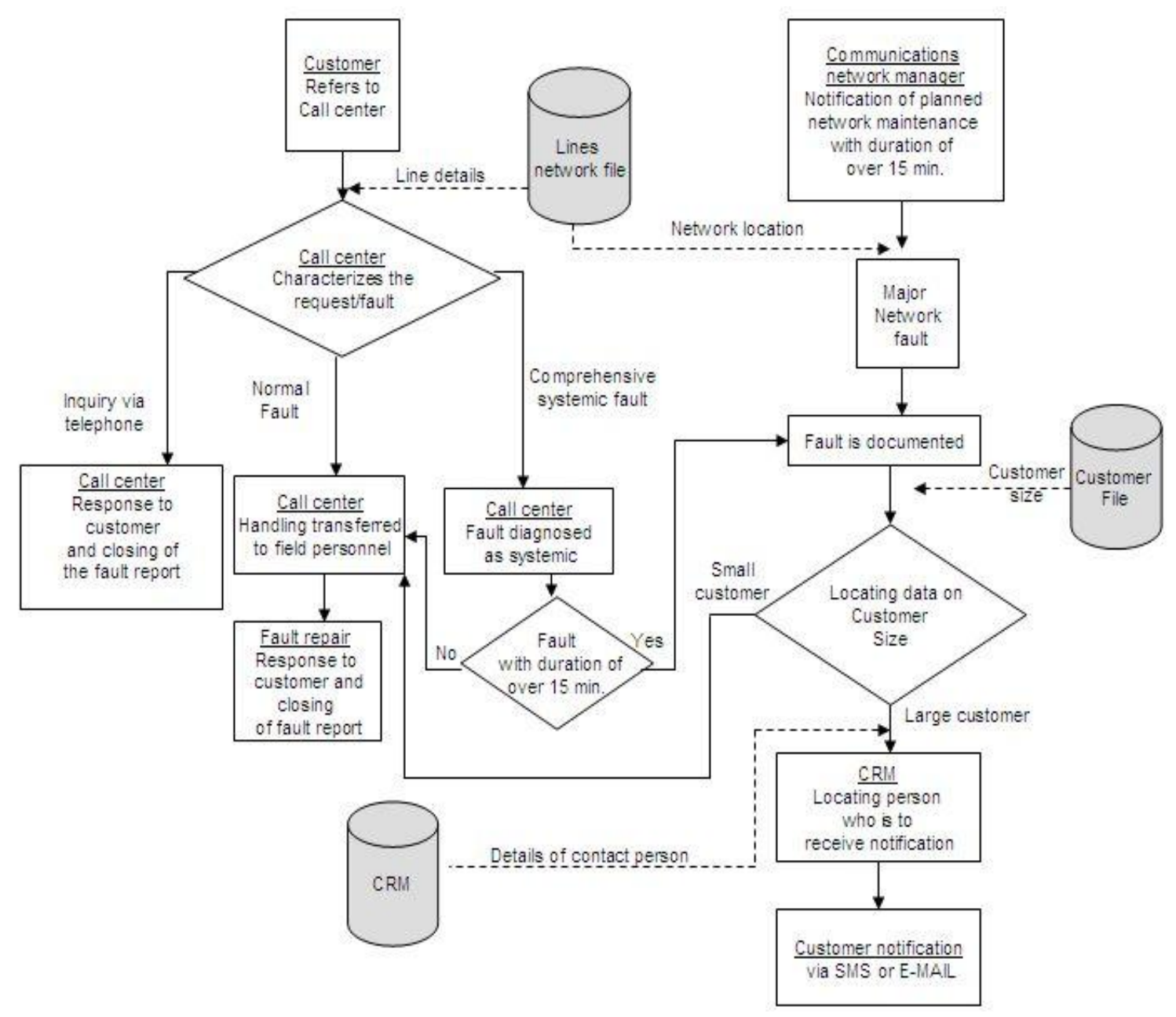

Figure 2: Customer notification processes for preventive maintenance and systemic faults 


\subsection{The Operation of Telco's Preventive Service System}

The company operates a CRM system that collects business data on customers. This information is used for data mining and classification of customers according to the financial value of the services that they use. The system includes details of the contact persons that are authorized to represent the customers during service failures. Additionally, the company operates a system which handles systemic failures and planned maintenance and automatically notifies customers about them (see the customer notification processes of the firm in Fig. 2).

When a service failure occurs, Telco's monitoring system identifies the group of communication lines that are affected by it and retrieves from the CRM system the contact details of customers that should be notified about the failure.

The company's method of operation includes the following principles:

- $\quad$ Provision of premium level services to a group of customers that contribute substantial revenues to the firm. The customers who are notified by the company when systemic failure or planned maintenance occur include those who pay on average more than $\$ 50,000$ per month for Telco's services, based on the historical data in the CRM system.

- $\quad$ Defining means of contact to these customers via SMS and email, sent to contact persons, since in case of a failure of telephone landlines customers cannot be notified.

- $\quad$ Determining minimum downtime before notifying key customers about service malfunctions and planned downtime, even when customer do not report any problems. When the company expects that the outage will continue more than fifteen minutes, it notifies the selected group of customers about it. This time frame was determined after consultation with customers. Telco avoids disturbing its customers with repetitive notifications about shorter outages and at the same time it allows them to take appropriate measures in case of prolonged outages.

The company delivers to customers three types of notification messages that correspond to three types of service discontinuities, as follows:

1) After assessing the malfunction, if Telco concludes that a systematic failure has occurred, the following message is sent to customers by SMS and by email:

Dear customer,

Thank you for notifying us about the fault in your communications equipment. The duration of fixing it will be over 15 minutes. The existing fault is a systematic problem that is located in [line identifier]. You are one of our most important customers and we do every effort to fix it as soon as possible. You will be notified when the problem will be solved.

Kind regards, [name] - Service Manager.

2) When the failure has been identified by Telco before customers have discovered it (and before they have contacted the helpdesk), the following message is sent:

Dear customer,

We identified a fault in your communications equipment in your [line identifier]. We do every effort to fix it as soon as possible. You will be notified when the problem will be solved.

Kind regards, [name] - Service Manager.

3) When maintenance activities are planned, the firm notifies its customers in advance by sending them the following notice: 
Dear customer,

As a part of Telco's efforts to provide you highly qualitative services, we will carry out maintenance activities. Consequently, our services will not be available on [day] between [hours] in lines/location [line identifiers/location identifier]. You are one of our most important customers and we do every effort to minimize the maintenance time and to provide our services as soon as possible.

Kind regards, [name] - Service Manager.

After notifying the customers about the service outage and completing the maintenance activities (caused by planned work or by service malfunctions), Telco notifies its customers about the activation of services. Further, even when service malfunctions occur while customers are not noticing them (for example, during night hours or after office hours), the company notifies them about the malfunction and about its activities to renew the service provision.

\section{DISCUSSION AND CONCLUSION}

The recent research on service and customer relationship management has largely focused on the sustainability of customer satisfaction and on the preservation of post-complaint customer loyalty. To an extent, literature has overlooked the possibilities of implementing systems that proactively monitor the service provision and eliminate occurrences that may result in the failure of service processes. Notably, broad surveys conducted by Roth and Menor (2003), Rust and Chung (2006), Rust and Miu (2006) and Chesbrough and Spohrer (2006) do not mention the systemic prevention of customer complaints among the wealth of suggested directions for the future research agenda in the field of service management and economics.

The majority of studies on service management emphasize the various mechanisms and customer oriented perspectives that aim at restoring service outages and their consequent damages to both customers and clients after they have occurred. This paper departs from the conventional perspectives on service management by establishing a new conceptual framework, the preventive service methodology, which is based on proactive approach towards prevention of service outages and the resulting damages to service providers and to customers.

To a large extent, the presented methodology signifies a unique and important paradigm shift with regards to the present perceptions of service management among firm managers and academicians. Currently, the majority of service providing organizations reacts to service malfunctions in an attempt to preserve their customers' satisfaction and loyalty. In this respect, the suggested methodology presents a new and innovative approach, as well as a practical toolkit, for preventing different sorts of service "shortages" and their negative outcomes.

In general, the majority of service providers, in particular telecommunications companies, do not send notices about service outages in advance, despite the benefits of notifying their customers about planned and unanticipated service malfunctions. By implementing the passive and active notification mechanisms, as this paper suggests, companies can improve customer relations in terms of providing alternative solutions for clients and preserving customer satisfaction and loyalty.

In this respect, the case of Telco is unique, as it illustrates some of the possibilities and the advantages of implementing preventive service tools that are not broadly implemented by firms in the telecommunications sector, despite the tangible benefits that they offer. In particular, an important concept that is included within the suggested methodology and has been implemented by Telco is the notification about service malfunctions that are expected to advance beyond a determined period of time, thereby preparing customers for longer service outages.

As communication lines (such as mobile, land-line and Internet channels) become increasingly important and signify the backbone of commercial transactions and relations, telecommunications become an essential means for the operation of organizations and firms. Therefore, when service outages are planned or unexpectedly happen and are identified via the firm's monitoring activities, the major customers are alerted to enable them to apply alternative protocols and communication systems and to minimize the damages and the risks to which they are 
exposed. By monitoring service malfunctions in advance on the basis of control and information systems, providers can detect potential problems in the delivery of their services before they occur or very close to the time of their occurrence.

The application of the preventive service methodology and tools can generate a variety of financial and service related benefits both for the firm and for its customers. Among them are continuous streams of revenues from its most important customers, improved degrees of customer satisfaction and strengthened relations between the firm and its consumers. The proposed methodology is generic in essence and can be extended, be modified and be applied by most of the firms that operate in the service and service-related sectors. Moreover, the paper presents an initial conceptual framework that offers new venues for developing new theoretical and empirical research in the fields of service management and information systems.

\section{AUTHOR INFORMATION}

Ofer Barkai, $\mathrm{PhD}$, is a Lecturer in the Department of Industrial and Management Engineering at the Shamoon College of Engineering, Be'er Sheva, Israel. In addition he has 27 years of industrial experience. He specializes in wage and compensation strategies at the organizational and managerial levels, compensation schemes, sectorial compensation and payment methods and service organization. E-mail: ofer@sce.ac.il

Elad Harison, $\mathrm{PhD}$, is a Senior Lecturer at the Department of Industrial Engineering and Management at the Shenkar College of Engineering and Design, Ramat Gan, Israel. He specializes in the Economics of Innovation and technical change in the context of information technologies. He was involved in several research projects on innovation policies and ICT for the European Commission and for several European governments. E-mail: eladha@shenkar.ac.il

\section{REFERENCES}

1. $\quad$ Anderson E.W., Fornell C., \& Lehmann D.R. (1994). Customer Satisfaction, Market Share and Profitability. Journal of Marketing, 58, 53-66.

2. Bolton R.N. (1998). A Dynamic Model of the Duration of the Customer's Relationship with a Continuous Service Provider: The Role of Satisfaction. Marketing Science, 17(1), 45-65.

3. Chebat J.C., Davidow M., \& Codjovi I. (2005). Silent Voices: Why Some Dissatisfied Consumers Fail to Complain. Journal of Service Research, 7(4), 328-342.

4. Chesbrough H., \& Spohrer J. (2006). A Research Manifesto for Service Science. Communications of the ACM, 49(7), 35-40.

5. Davidow M. (2003). Organizational Responses to Customer Complaints: What Works and What Doesn't. Journal of Service Research, 5(3), 225-250.

6. Duffy J.A.M., Miller J.M., \& Bexley J.B. (2006). Banking customers' varied reactions to service recovery strategies. International Journal of Bank Marketing, 24, 112-132.

7. Fornell C., \& Wernerfelt B. (1987). Defensive Marketing Strategy by Customer Complaint Management: A Theoretical Analysis. Journal of Marketing Research, 24, 337-346.

8. Gupta S., \& Zeithaml V. (2006). Customer Metrics and their Impact on Financial Performance. Marketing Science, 25, 718-739.

9. $\quad$ Hart C.W.L., Heskett J.L., \& Sasser W.E. (1990). The Profitable Art of Service Recovery. Harvard Business Review, July-August 1990, 148-156.

10. Homburg C., Fürst A., \& Koschate N. (2010). On the importance of complaint handling design: a multilevel analysis of the impact in specific complaint situations. Journal of the Academy of Marketing Science, $38,265-287$.

11. Johnston R. (2001). Linking Complaint Management to Profit. Journal of Service Management, 12, 60-69.

12. Loveman G.W. (1998). Employee Satisfaction, Customer Loyalty and Financial Performance: An Empirical Examination of the Service Profit Chain in Retail Banking. Journal of Service Research, 1, 1831.

13. Luo X., \& Bhattacharya C.B. (2006). Corporate Social Responsibility, Customer Satisfaction, and Market Value. Journal of Marketing, 70, 1-18. 
14. Maxham J.G. (2001). Service recovery's influence on consumer satisfaction, positive word-of-mouth and purchase intentions. Journal of Business Research, 54, 11-24.

15. Maxham J.G., \& Netemeyer R.G. (2002). A Longitudinal Study of Complaining Customers' Evaluations of Multiple Service Failures and Recovery Efforts. Journal of Marketing, 66, 57-71.

16. Miller J.L., Craighead C.W., \& Karwan K.R. (2000). Service recovery: a framework and empirical investigation. Journal of Operations Management, 18, 387-400.

17. Radas S., \& Shugan S.M. (1998). Managing Service Demand: Shifting and Bundling. Journal of Service Research, 1, 47-64.

18. Roth A.V., \& Menor L.J. (2003). Insights into Service Operations Management: A Research Agenda. Production and Operations Management, 12, 145-164.

19. Rust R.T., Zahorik A.J., \& Keiningham T.L. (1995). Return on Quality (ROQ): Making Service Quality Financially Accountable. Journal of Marketing, 59, 58-70.

20. Rust R.T., \& Miu C. (2006). What Academic Research Tells Us About Service. Communications of the ACM, 49, 49-54.

21. Rust R.T., \& Chung T.S. (2006). Marketing Models of Service and Relationships. Marketing Science, 25, 560-580.

22. Sharma P., Marshall R., Reday P.A., \& Na W. (2010). Complainers versus non-complainers: a multinational investigation of individual and situational influences on customer complaint behaviour. Journal of Marketing Management, 26, 163-180.

23. Tucker A.L., \& Edmondson A.C. (2003). Why hospitals don't learn from failures: Organizational and psychological dynamics that inhibit system change. California Management Review, 45, 1-18. 